\title{
Pemeriksaan Bone Mineral Density dan Pelatihan Senam Osteoporosis Sebagai Upaya Peningkatan Kewaspadaan Osteoporosis pada Penderita Talasemia Mayor
}

\author{
Nyoman Suci Widyastiti, I Edward KSL, Meita Hendrianingtyas, Ariosta, \\ Dwi Retnoningrum, Dwi Ngestiningsih, Yetty Movieta Nency \\ Universitas Diponegoro, Semarang, Indonesia \\ nyoman.suci@fk.undip.ac.id
}

Received: $12^{\text {th }}$ September $2020 \mid$ Accepted: $19^{\text {th }}$ July $2021 \mid$ Published: $27^{\text {th }}$ July 2021

\begin{tabular}{|c|c|}
\hline Key word: & $\begin{array}{l}\text { Abstract } \\
\text { Thalassemia major patients with routine transfusions are at risk of } \\
\text { experiencing iron overload and bone turn over disorders which will }\end{array}$ \\
\hline $\begin{array}{l}\text { Major } \\
\text { thalassemia; } \\
\text { bone mineral } \\
\text { density; } \\
\text { osteoporosis }\end{array}$ & $\begin{array}{l}\text { increase the risk of osteoporosis. Community training activities with } \\
\text { BMD examinations and osteoporosis exercise training in thalassemia } \\
\text { major patients are expected to identify the prevalence of bone fragility in } \\
\text { thalassemia major patients, increase the awareness of thalassemia major } \\
\text { patients and their families to the risk of osteoporosis in thalassemia major } \\
\text { patients and osteoporosis exercise training as an effort to prevent } \\
\text { osteroporosis. The results of BMD on the spine showed } 57.1 \% \\
\text { osteoporosis, } 28.6 \% \text { normal and } 14.3 \% \text { osteopenia. The results of BMD } \\
\text { examination on the cervical spine showed } 71.4 \% \text { osteopenia, } 21.4 \% \\
\text { normal and } 7.2 \% \text { osteoporosis. The results of BMD examination on the } \\
\text { femur found } 50 \% \text { normal, } 42.8 \% \text { osteopenia and } 7.2 \% \text { osteoporosis. The } \\
\text { bone location with the highest percentage of osteoporosis was the spine } \\
\text { (57\%), and the bone location with the highest percentage of osteopenia } \\
\text { was the neck bone (71.4\%). The high percentage of osteopenia locations in } \\
\text { the cervical spine of thalassemia major patients with repeated transfusions } \\
\text { should be become a concern. Based on these findings, we held education } \\
\text { and counselling on the risk of osteoporosis in thalassemia patients with } \\
\text { repeated transfusions, osteoporosis exercise training and distribution of } \\
\text { osteoporosis exercise compact disk (CD) for at home osteoporosis exercise } \\
\text { training. }\end{array}$ \\
\hline Kata Kunci & $\begin{array}{l}\text { Abstrak } \\
\text { Pasien talasemia mayor dengan transfusi rutin berisiko mengalami iron } \\
\text { overload dan gangguan bone turn over yang akan meningkatkan risiko }\end{array}$ \\
\hline $\begin{array}{l}\text { Talasemia } \\
\text { mayor; } \\
\text { kepadatan } \\
\text { mineral tulang; } \\
\text { osteoporosis }\end{array}$ & $\begin{array}{l}\text { terjadinya osteroporosis. Kegiatan pengabdian masyarakat dengan } \\
\text { pemeriksaan BMD dan pelatihan senam osteoporosis pada pasien } \\
\text { talasemia mayor diharapkan akan mengidentifikasi prevalensi kerapuhan } \\
\text { tulang pada pasien talasemia mayor, meningkatkan kewaspadaan pasien } \\
\text { talasemia mayor dan keluarganya terhadap risiko osteoporosis pada pasien } \\
\text { talasemia mayor serta pelatihan senam osteoporosis sebagai upaya } \\
\text { pencegahan osteroporosis.Hasil pemeriksaan BMD pada tulang belakang } \\
\text { terdapat } 57,1 \% \text { osteoporosis, } 28,6 \% \text { normal dan } 14,3 \% \text { osteopenia. Hasil } \\
\text { pemeriksaan BMD pada tulang leher terdapat } 71,4 \% \text { osteopenia, } 21,4 \% \\
\text { normal dan } 7,2 \% \text { osteoporosis. Hasil pemeriksaan BMD pada tulang } \\
\text { paha didapatkan } 50 \% \text { normal, } 42,8 \% \text { osteopenia dan } 7,2 \% \text { osteoporosis. }\end{array}$ \\
\hline
\end{tabular}


Lokasi tulang dengan persentase osteoporosis tertinggi ialah tulang belakang (57\%), dan lokasi tulang dengan persentase osteopenia tertinggi ialah tulang leher (71,4\%). Terdapat kerapuhan tulang (osteoporosis dan osteopenia) dengan persentase yang sangat tinggi pada penderita talasemia mayor dengan transfusi berulang. Tingginya persentase lokasi osteopenia pada tulang leher penderita talasemia mayor dengan transfusi berulang perlu menjadi perhatian. Berdasarkan temuan tersebut, dilakukan penyuluhan risiko osteoporosis pada penderita talasemia dengan tansfusi berulang, pelatihan senam osteoporosis dan pembagian Compact Disk (CD) senam osteoporosis untuk senam osteoporosis mandiri.

\section{PENDAHULUAN}

Talasemia merupakan kelompok kelainan yang diturunkan karena terjadi mutasi atau delesi pada gen yang menyandikan salah satu rantai globin sehingga terjadi penurunan kecepatan sintesis, atau ketiadaan sintesis, dari rantai yang setara. Hal ini menyebabkan penurunan kecepatan sintesis hemoglobin dan terjadi anemia dengan gambaran mikrositosis (Modell \& Darlison, 2008).

Prevalensi talasemia di dunia sekitar 4,4 setiap 10.000 kelahiran (Smith, 2015). Hasil riset kesehatan dasar (Riskesdas) tahun 2007 menunjukkan prevalensi nasional talasemia adalah $0,1 \%$. Berdasarkan survey prevalensi talasemia di propinsi DI Aceh 13,4 \%, DKI Jakarta $12,3 \%$, Sumatera Selatan 5,4\%, Jawa Tengah 0,5\%, Lampung 0,1\%(Kemkes RI, 2012).

Jawa Tengah yang memiliki luas wilayah $373,7 \mathrm{~km} 2$ dengan 16 kecamatan. Jumlah penduduk kota Semarang tahun 2015 adalah 1.595.187 penduduk, dengan 49,7\% jenis kelamin laki-laki dan 50,3\% jenis kelamin perempuan.4 Berdasarkan data di RSUD dr.R. Soedjati Kabupaten Grobogan dan di RSUD dr.R Soetrasno Kabupaten Rembang, tercatat terdapat 15 pasien thalasemia mayor yang menjalani transfusi rutin di RSUD dr.R. Soedjati Kabupaten Grobogan dan 15 pasien talasemia mayor yang menjalani transfusi rutin di RSUD dr.R Soetrasno Kabupaten Rembang (Harahap dkk., 2020).

Di Indonesia sendiri telah berdiri Yayasan talasemia Indonesia, yang telah didirikan pada tanggal 27 Mei 1987 yang mempunyai kegiatan antara lain membantu pemerintah dalam upaya menyelamatkan generasi penerus yang bebas dari penyakit talasemia, meringankan beban para orang tua penderita talasemia, mengurangi meningkatnya penderita talasemia dan mendirikan pusat kegiatan talasemia (Thalassaemia Centre) dibeberapa daerah (Yayasan Thalassaemia Indonesia, 2016). Meskipun telah dilakukan upaya baik regional maupun program pencegahan talasemia secara nasional, angka kejadian talasemia di Indonesia khususnya di Kabupaten Rembang dan Kabupaten Grobogan masih meningkat. 


\begin{abstract}
Pengelolaan talasemia secara komprehensif mencakup pencegahan kejadian talasemia mayor dan penanganan pasien talasemia mayor (transfusi darah dan pengelolaan komplikasi) (Beutler dkk., 2003). Talasemia mayor atau transfusion dependent thalassemia ialah talasemia berat yang membutuhkan transfusi rutin dan berkelanjutan. Talasemia mayor membutuhkan biaya yang sangat besar karena membutuhkan transfusi rutin dan berkelanjutan, serta membutuhkan obatobatan yang mahal untuk mencegah timbunan zat besi (iron overload) akibat transfusi berulang (Hoffbrand \& Steensma, 2019).
\end{abstract}

Penderita talasemia mayor dengan anemia berat (kadar $\mathrm{Hb}$ dibawah $7 \mathrm{gr} / \mathrm{dl}$ ) harus mendapatkan transfusi darah seumur hidup untuk mengatasi anemia dan mempertahankan kadar hemoglobin 9-10 gr/dl. Eritrosit mengandung besi sebesar 1 $\mathrm{mg} / \mathrm{mL}$, sehingga bila 1 kantong darah berisikan $450 \mathrm{~mL}$ whole blood atau 200 $\mathrm{mL}$ packed red cell maka akan menambahkan besi sejumlah $200 \mathrm{mg}$ kepada resipien, dalam hal ini penderita talasemia. Pemberian transfusi darah yang berulang dapat menimbulkan komplikasi hemosiderosis dan hemokromatosis, yaitu menimbulkan penimbunan zat besi dalam jaringan tubuh (iron overload) sehingga dapat menyebabkan kerusakan organ-organ tubuh seperti hati, limpa, ginjal, jantung, tulang dan pancreas (Hoffbrand \& Steensma, 2019).

Efek samping penumpukan besi (hemokromatosis) pada hepar adalah dapat memicu peningkatan zat besi bebas yang selanjutnya terbentuk radikal bebas melalui reaksi Fenton. Zat ini bersifat hepatotoksik dan mengganggu metabolisme vitamin D.Homeostasis kalsium yang terganggu dianggap sebagai konsekuensi dari kelebihan zat besi akibat transfusi berulang. Cacat produksi dari 25-hydroxyvitamin D telah diketahui secara negatif mempengaruhi metabolisme tulang (Wong dkk., 2016). Penyakit tulang menjadi penyebab morbiditas yang penting pada talasemia, meliputi osteoporosis, rakhitis, skoliosis, deformitas tulang belakang, kompresi saraf dan fraktur (Toxqui \& Vaquero, 2015).

Osteoporosis adalah suatu keadaan yang ditandai dengan massa tulang yang rendah dan kerusakan pada jaringan di dalam tulang. Pada osteoporosis, terjadi penurunan kualitas dan kuantitas kepadatan tulang sehingga penderita osteoporosis mudah terjadi fraktur . Upaya untuk mencegah komplikasi osteoporosis dan fraktur pada penderita talasemia mayor dengan transfusi berulang adalah pengukuran bone mineral density (BMD) (Toumba \& Skordis, 2010). Pemeriksaan 
BMD dengan densitometer ini bermanfaat untuk mengidentifikasi penurunan massa tulang seorang penderita sehingga dapat meminimalkan risiko fraktur. Salah satu upaya untuk mencegah dan mengobati osteoporosis adalah dengan melakukan senam osteoporosis (Zoga dkk., 2014). Prinsip latihan fisik untuk kesehatan tulang adalah latihan pembebanan, gerakan dinamis dan ritmis, serta latihan daya tahan (endurans) dalam bentuk aerobic low impact. Semua jenis latihan ini telah dikemas dalam bentuk Senam Pencegahan Osteoporosis dan Senam Terapi Osteoporosis.

Kejadian talasemia mayor dengan transfusi berulang semakin meningkat di masyarakat, khususnya di Kabupaten Rembang dan Kabupaten Grobogan, Jawa Tengah. Penderita talasemia mayor membutuhkan transfusi seumur hidup karena tanpa transfusi yang memadai penderita talasemia mayor akan meninggal pada dekade kedua.

Masyarakat kurang memahami bahwa transfusi berulang dapat menyebabkan komplikasi akibatiron overload yang membutuhkan pencegahan dan penatalaksanaan. Iron overload dapat menyebabkan gangguan pada metabolisme vitamin D dan kalsium. Gangguan metabolisme vitamin D dan kalsium dapat menyebabkan gangguan metabolisme tulang. Penyakit tulang yang menyebabkan morbiditas yang penting pada penderita talasemia mayor adalah osteoporosis dan fraktur.

Berdasarkan permasalahan yang ada, diperlukan suatu pemeriksaan pada penderita talasemia mayor dengan transfusi berulang untuk mengetahui komplikasi osteoporosis pada tulang, yaitu dengan pemeriksaan bone mineral density (BMD) dengan densitometer. Pemeriksaan BMD dapat mengetahui kepadatan tulang sehingga penderita dengan risiko tinggi osteoporosis dapat diketahui.

Selain itu juga diperlukan pencegahan dan penatalaksaaan komplikasi osteoporosis pada penderita talasemia, salah satunya dengan senam osteoporosis.

\section{METODE}

Metode yang digunakan dalam pengabdian ini adalah sebagai berikut:

1. Pendekatan kepada masyarakat untuk meningkatkan pemahaman mengenai talasemia serta penatalaksaannya

2. Pendekatan kepada masyarakat untuk meningkatkan pemahaman mengenai iron overload pada transfusi berulang dan komplikasi osteroporosis akibat gangguan metabolisme vitamin $\mathrm{D}$ dan kalsium 
3. Pemeriksaan bone mineral density (BMD) pada penderita talasemia mayor dengan transfusi berulang

4. Pelatihan dan pelaksanaan senam osteoporosis pada penderita talasemia mayor dengan transfusi berulang untuk mencegah osteroporosis dan fraktur.

\section{HASIL}

Sebelum dilakukan pemeriksaan BMD pada pasien talasemia dengan transfusi berulang, tim pengabdian masyarakat mengajukan perizinan kepada mitra, yaitu RSUD dr.R Soetrasno Kabupaten Rembang dan RSUD Dr. R Soedjati, Kab. Grobogan, sebagai tempat pelayanan kesehatan pasien anak talasemia yang rutin transfusi di tempat tersebut. Identifikasi sasaran pasien adalah melalui anamnesis, pemeriksaan fisik dan riwayat pemeriksaan laboratorium darah lengkap. Data karakteristik pasien tersaji dalam tabel 1 .

Tabel 1. Karakteristik pasien

\begin{tabular}{|c|c|c|c|c|c|c|}
\hline Karakteristik subjek & Frekuensi & $\%$ & $\begin{array}{c}\text { Rerata } \\
\pm \text { SB } \\
\end{array}$ & Median & Min & $\operatorname{Max}$ \\
\hline Demografis & & & & 10 & 6 & 16 \\
\hline Usia (tahun) & & & $10.12 \pm 2.61$ & & & \\
\hline 06-10 tahun & 17 & & & & & \\
\hline 11-19 tahun & 11 & & & & & \\
\hline \multicolumn{7}{|l|}{ Jenis kelamin } \\
\hline Laki-laki & 12 & $42,8 \%$ & & & & \\
\hline Perempuan & 16 & $57,2 \%$ & & & & \\
\hline \multicolumn{7}{|l|}{ Transfusi dan khelasi } \\
\hline $\mathrm{Hb}(\mathrm{gr} / \mathrm{dL})$ & & & $9.56 \pm 1.79$ & 9.4 & 6.6 & 13.5 \\
\hline $\mathrm{Hb}<9 \mathrm{gr} / \mathrm{dL}$ & 9 & $32.1 \%$ & & & & \\
\hline $\mathrm{Hb} \geq 9 \mathrm{gr} / \mathrm{dL}$ & 19 & $67.9 \%$ & & & & \\
\hline Lama transfusi (tahun) & & & $6.5 \pm 2.42$ & 7 & 1 & 13 \\
\hline \multicolumn{7}{|l|}{ Frekuensi transfusi } \\
\hline 1 kali/ bulan & 27 & $96,4 \%$ & & & & \\
\hline 1 kali/ 2 bulan & 1 & $3,6 \%$ & & & & \\
\hline \multicolumn{7}{|l|}{ Jumlah transfusi } \\
\hline $10-20 \mathrm{kali}$ & 1 & $3.6 \%$ & & & & \\
\hline$>20$ kali & 27 & $96.4 \%$ & & & & \\
\hline \multicolumn{7}{|l|}{ Terapi khelasi besi } \\
\hline $\mathrm{Ya}$ & 25 & $89.3 \%$ & & & & \\
\hline Deferasirox & 21 & $75 \%$ & & & & \\
\hline Defreriprone & 4 & $25 \%$ & & & & \\
\hline Tidak & 3 & $10.7 \%$ & & & & \\
\hline
\end{tabular}

Sumber: Data Primer

Dari seluruh pasien talasemia pasien, terdiri dari $12(42,8 \%)$ pasien pria dengan transfusi berulang yang rutin transfusi di RSUD Kab. Grobogan dan RSUD Kab. Rembang terdapat 28 pasien yang masuk dalam identifikasi sasaran dan $16(57,2 \%)$ pasien wanita. Proporsi jenis kelamin tersebut sesuai dengan teori bahwa talasemia merupakan kelainan herediter yang mengenai sintesis rantai 
globin yang diwarisi oleh salah satu atau kedua orang tuanya secara autosomal resesif dan berpengaruh yang sama terhadap jenis kelamin pria dan wanita.

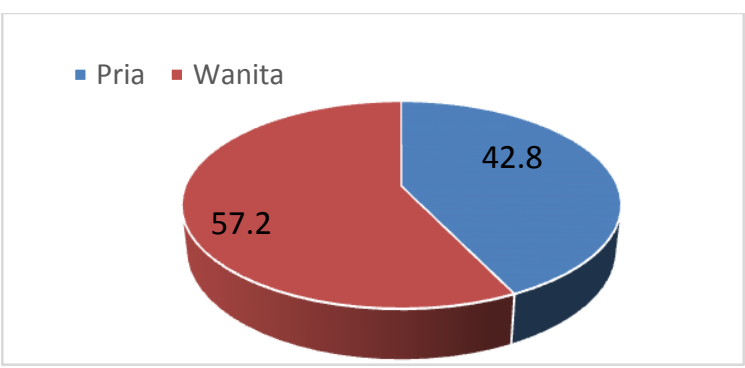

Gambar 1. Prosentase jenis kelamin

Usia pasien termuda adalah usia 6 tahun dan usia tertua 16 tahun, dengan rerata usia $10.12 \pm 2.61$ tahun. Pasien pada umumnya mengalami anemia yang berlanjut dan selalu membutuhkan transfusi. Tujuan transfusi darah pada pasien talasemia adalah untuk menekan hematopoiesis ekstramedular dan mengoptimalkan tumbuh kembang anak. Kebutuhan jumlah unit darah packed red cell disesuaikan dengan usia, kadar $\mathrm{Hb}$ dan berat badan pasien tersebut. Banyaknya unit yang diterima berkisar satu unit sampai dua unit setiap kali transfusi.

Pemeriksaan hematologi pretransfusi didapatkan rerata $\mathrm{Hb} \quad 9.56 \pm 1.79 \mathrm{gr} / \mathrm{dL}$ dengan kadar $\mathrm{Hb}$ yang bervariasi yaitu $\mathrm{Hb}$ terendah 6,6 gram/dL dan tertinggi 13,5 gram/dL. Nilai $\mathrm{Hb}$ sesuai dengan gambaran darah tepiberupa anemia derajat sedang - berat sehingga memerlukan transfusi berkelanjutan. Rerata $\mathrm{Hb}$ pretransfusi sudah memenuhi target $\mathrm{Hb}$ tetapi 9 dari 28 subjek penelitian $(32,1 \%)$ masih memiliki $\mathrm{Hb}<9 \mathrm{gr} / \mathrm{dL}$. Gambar 2A menunjukkan $\mathrm{Hb}$ pasien talasemia. $\mathrm{Hb}$ pretransfusi seyogyanya dipertahankan antara 9-10 g/dL dapat mencegah terjadinya hemopoesis ekstramedular dan mengurangi absorpsi besi dari saluran cerna, sehingga pasien rutin transfusi pada periode waktu tertentu.

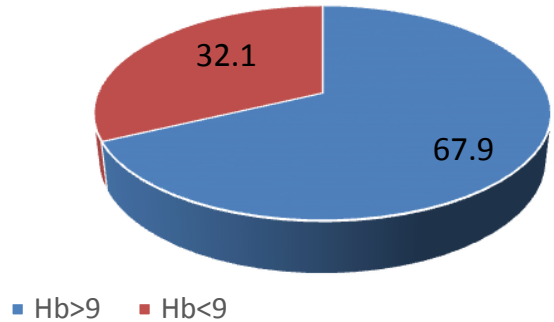

Gambar 2. Persentase tingkat $\mathrm{Hb}$ pasien talasemia

Gambar 3 menunjukkan bahwa hampir seluruh pasien mendapat transfusi 1 kali dalam sebulan.

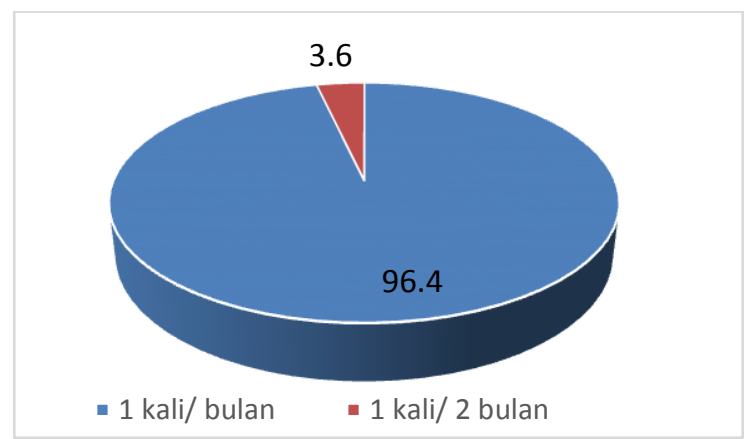

Gambar 3. Persentase frekuensi transfusi

Hasil pemeriksaan BMD pada 14 pasien thalasemia mayor di RSUD Dr. Soedjati, Grobogan ditampilkan pada tabel 2. Pemeriksaan BMD dilakukan pada 3 lokasi tulang, yaitu spine (tulang belakang), 
neck (leher) dan femur (tulang paha). Berdasarkan hasil pemeriksaan BMD tersebut tampak bahwa 2 orang $(14,3 \%)$ pasien thalasemia mayor mempunyai nilai BMD yang normal dan 12 orang $(85,7 \%)$ memiliki nilai BMB rendah (osteopenia Tabel 2. Hasil pemeriksaan BMD atau osteoporosis) pada satu, dua atau ketiga lokasi tulang yang dilakukan pemeriksaan BMD. Mayoritas (85,7\%) pasien thalasemia mengalami osteopenia pada satu, dua atau tiga lokasi tulang yang dilakukan pemeriksaan BMD.

\begin{tabular}{|c|c|c|c|c|c|}
\hline \multirow[t]{2}{*}{ No } & \multirow{2}{*}{$\begin{array}{l}\text { Umur } \\
\text { (tahun) }\end{array}$} & \multirow{2}{*}{$\begin{array}{l}\text { Jenis } \\
\text { Kelamin }\end{array}$} & \multicolumn{3}{|c|}{$\begin{array}{l}\text { Hasil Bone Mineral Density } \\
\end{array}$} \\
\hline & & & AP spine (L1-L4) & Neck & Total Femur \\
\hline 1 & 13 & $\mathrm{~L}$ & Osteoporosis & Osteopenia & Osteopenia \\
\hline 2 & 10 & $\mathrm{P}$ & Normal & Osteopenia & Normal \\
\hline 3 & 7 & $\mathrm{~L}$ & Normal & Normal & Normal \\
\hline 4 & 9 & $\mathrm{P}$ & Normal & Normal & Normal \\
\hline 5 & 11 & $\mathrm{~L}$ & Osteoporosis & Osteoporosis & Osteoporosis \\
\hline 6 & 8 & $\mathrm{P}$ & Osteoporosis & Osteopenia & Normal \\
\hline 7 & 9 & $\mathrm{P}$ & Osteopenia & Normal & Normal \\
\hline 8 & 7 & $\mathrm{~L}$ & Osteoporosis & Osteopenia & Normal \\
\hline 9 & 9 & $\mathrm{~L}$ & Osteoporosis & Osteopenia & Osteopenia \\
\hline 10 & 8 & $\mathrm{P}$ & Osteoporosis & Osteopenia & Osteopenia \\
\hline 11 & 11 & $\mathrm{P}$ & Osteopenia & Osteopenia & Osteopenia \\
\hline 12 & 12 & $\mathrm{P}$ & Osteoporosis & Osteopenia & Osteopenia \\
\hline 13 & 7 & $\mathrm{P}$ & Osteoporosis & Osteopenia & Osteopenia \\
\hline 14 & 9 & $\mathrm{~L}$ & Normal & Osteopenia & Normal \\
\hline
\end{tabular}

Sumber: Data Primer

Persentase tingkat karapuhan tulang berdasar lokasi tulang yang diperiksa ditampilkan pada tabel 3. Hasil pemeriksaan BMD pada tulang belakang terdapat $57,1 \%$ osteoporosis, 28,6 \% normal dan 14,3\% osteopenia. Hasil pemeriksaan BMD pada tulang leher terdapat $71,4 \%$ osteopenia, $21,4 \%$ normal dan 7,2\% osteoporosis. Hasil pemeriksaan BMD pada tulang paha didapatkan 50\% normal, $42,8 \%$ osteopenia dan 7,2\% osteoporosis. Tampak bahwa lokasi tulang dengan persentase osteoporosis tertinggi ialah tulang belakang, dimana ditemukan osteoporosis 57\%, dan lokasi tulang dengan persentase osteopenia tertinggi ialah tulang leher $(71,4 \%)$. Temuan ini berbeda dengan pasien osteoporosis non thalasemia, dimana kerapuhan tulang terutama ditemukan pada tulang belakang, pinggul (pangkal paha) dan pergelangan tangan. Tingginya persentase lokasi osteopenia pada tulang leher penderita thalasemia mayor dengan transfusi berulang perlu menjadi perhatian karena temuan tersebut berbeda dengan penderita osteoporosis non thalasemia. 
Tabel 3. Sebaran kerapuhan tulang dari hasil BMP berdasar lokasi tulang yang diperiksa

\begin{tabular}{|c|c|c|c|c|c|c|}
\hline \multirow[t]{3}{*}{ Hasil BMD } & \multicolumn{6}{|c|}{ Lokasi } \\
\hline & \multicolumn{2}{|c|}{ AP spine (L1-L4) } & \multicolumn{2}{|c|}{ Neck } & \multicolumn{2}{|c|}{ Total Femur } \\
\hline & Jumlah & $\%$ & Jumlah & $\%$ & Jumlah & $\%$ \\
\hline Osteoporosis & 8 & $57,1 \%$ & 1 & $7,2 \%$ & 1 & $7,2 \%$ \\
\hline Osteopenia & 2 & $14,3 \%$ & 10 & $71,4 \%$ & 6 & $42,8 \%$ \\
\hline Normal & 4 & $28,6 \%$ & 3 & $21,4 \%$ & 7 & $50,0 \%$ \\
\hline
\end{tabular}

Sumber: Data Primer

Berdasarkan hasil pemeriksaan tersebut dapat disimpulkan bahwa sesuai telusur pustaka bahwa penderita thalasemia mayor dengan transfusi berulang memiliki risiko terjadi kerapuhan tulang. Dari hasil pemeriksaan BMD pasien thalasemia mayor dengan transfusi berulang di lokasi pengabdian masyarakat, terdapat $85,7 \%$ pasien thalasemia mengalami kerapuhan tulang (osteopenia atau osteoporosis) pada satu, dua atau tiga lokasi tulang yang dilakukan pemeriksaan BMD dengan persentase lokasi osteoporosis tertinggi ditemukan pada tulang leher dan persentase lokasi osteopenia tertinggi ditemukan pada tulang belakang (Lumbal $1-4)$.

\section{PEMBAHASAN}

Seorang dengan kerapuhan tulang (osteopenia atau osteoporosis) memiliki risiko untuk terjadi fraktur. Upaya untuk mencegah osteopenia dan osteoporosis antara lain ialah dengan kegiatan fisik berupa senam pencegahan osteoporosis. Kegiatan pengabdian masyarakat pada penderita thalasemia mayor dengan transfusi berulang dilanjutkan dengan penyuluhan dan kegiatan pelatihan senam osteoporosis yang diikuti oleh seluruh penderita thalasemia mayor yang mendapat transfusi berulang (Olivia dkk., 2017). Kegiatan senam itu harus dilakukan secara teratur dan berkelanjutan. Sebagai panduan kegiatan senam berkelanjutan (mandiri) setelah kegiatan senam bersama, dibagikan CD berisi rekaman senam osteoporosis yang dapat digunakan sebagai panduan dan penyemangat penderita thalasemia mayor untuk rutin melakukan senam osteoporosis secara mandiri di rumah (Cahyati dkk., 2021).

\section{SIMPULAN}

Telah dilakukan kegiatan pengabdian masyarakat yaitu identifikasi risiko osteoporosis menggunakan pemeriksaan Bone Mineral Density (BMD) dan pelatihan senam osteoporosis sebagai upaya peningkatan kewaspadaan dan pencegahan kejadian osteoporosis pada 

penderita thalasemia mayor dengan transfusi berulang.

$$
\text { Berdasar temuan hasil }
$$
pemeriksaan BMD, terdapat perbedaan
mayor dengan transfusi berulang dengan memperhatikan risiko kerapuhan tulang yang sebagian besar ditemukan pada tulang leher.

pola lokasi osteoporosis pada penderita thalasemia mayor dengan transfusi berulang bila dibandingkan dengan penderita osteoporosis tanpa transfusi berulang. Persentase osteoporosis pada penderita thalasemia mayor dengan transfusi berulang sangat tinggi pada tulang leher. Berdasar temuan tersebut, upaya pencegahan osteoporosis pada penderita thalasemia mayor dengan transfusi berulang dengan aktifitas senam osteoporosis sebaiknya memperhatikan temuan tersebut. Kegiatan senam osteoporosis banyak dilakukan pada lanjut usia dan populasi yang berisiko mengalami osteoporosis. Kegiatan senam tersebut dilakukan dengan panduan senam osteoporosis yang mudah ditemukan dan sering dilaksanakan pada kegiatan senam lansia.

\section{SARAN}

Hingga saat ini belum ditemukan panduan senam osteoporosis bagi penderita thalasemia dengan transfusi berulang, dimana persentase kerapuhan tulang (osteoporosis) banyak ditemukan di tulang leher. Oleh karena itu di masa mendatang diharapkan terdapat panduan senam osteoporosis bagi penderita thalasemia

\section{UCAPAN TERIMA KASIH}

Ucapan terima kasih kepada Universitas Diponegoro, Direktur RSUD dr. R Soetrasno Kabupaten Rembang dan RSUD Dr. R Soedjati, Kab. Grobogan, pasien talasemia dan semua pihak yang mendukung terlaksananya kegiatan pengabdian kepada masyarakat ini.

\section{DAFTAR PUSTAKA}

Beutler, E., Hoffbrand, A. V., \& Cook, J. D. (2003). Iron deficiency and overload. ASH Education Program Book, 2003(1), 40-61.

Cahyati, Y., Rosdiana, I., \& Indriani, N. (2021). Upaya Pemberdayaan Masyarakat Melalui Edukasi Pembentukan Posbindu PTM di Wilayah Kerja Puskesmas Kahuripan Kota Tasikmalaya. Jurnal Pengabdian Masyarakat (Jupemas), 2(1).

Harahap, N. K., Mulyono, M., Nency, Y. M., \& Widyastiti, N. S. (2020). ASSOCIATION BETWEEN 25-
HYDROXYVITAMIN D LEVELS
AND GROWTH PARAMETERS
IN THALASSEMIA WITH Tindakan Keperawatan Mandiri \& 
REPEATED BLOOD

TRANSFUSION. DIPONEGORO

MEDICAL JOURNAL (JURNAL

KEDOKTERAN DIPONEGORO),

$9(6), 422-428$.

Hoffbrand, A. V., \& Steensma, D. P. (2019). Hoffbrand's essential haematology. John Wiley \& Sons.

Kemkes RI, P. K. P. (2012, Juni 2).

Thalasemia Bukan Penyakit

Menular. Sehat Negeriku.

https://sehatnegeriku.kemkes.go.id/ baca/rilis-

media/20120602/496533/thalasemi

a-bukan-penyakit-menular/

Modell, B., \& Darlison, M. (2008). Global epidemiology of haemoglobin disorders and derived service indicators. Bulletin of the World

Health Organization, 86, 480-487.

Olivia, Z., Suryana, A. L., \& Arum, P.

(2017). Deteksi Dini Osteoporosis serta Upaya Pencegahannya dengan Pengaturan Diet dan Suplementasi Gizi di UPT Pelayanan Sosial Tresna Werdha Jember. Prosiding.

Smith, Y. (2015). Thalassemia Prevalence.

News Medical. https://www.newsmedical.net/health/ThalassemiaPrevalence.aspx

Toumba, M., \& Skordis, N. (2010).

Osteoporosis syndrome in thalassaemia major: An overview. Journal of osteoporosis, 2010.

Toxqui, L., \& Vaquero, M. P. (2015).

Chronic iron deficiency as an emerging risk factor for osteoporosis: A hypothesis. Nutrients, 7(4), 2324-2344.

Wong, P., Fuller, P. J., Gillespie, M. T., \& Milat, F. (2016). Bone disease in thalassemia: A molecular and clinical overview. Endocrine reviews, 37(4), 320-346.

Yayasan Thalassaemia Indonesia. (2016).

Tentang POPTI. Yayasan

Thalassaemia Indonesia.

Zoga, J., Refatllari, E., Allkanjari, A., Llika, D., Kallco, M., \& Zaka, A. (2014). Biochemical markers of bone disease in patients with $\beta$ thalassaemia major in the center of hemoglobinopathy Lushnja, Albania. Int J Health Sci Res, 4(12), 139-143. 